\title{
Minor and Trace Element Analysis in Breast Milk Using Inductively Coupled Plasma Mass Spectrometry (ICP-MS)
}

\author{
Liuchun Yang ${ }^{1}$, Meng Zhang ${ }^{1}$, Shen Lin ${ }^{1}$, Dengyun Chen ${ }^{2}$, and Minghui Zheng ${ }^{1, *}$ \\ 1 Research Center for Eco-Environmental Sciences, Chinese Academy of Sciences, P.O. Box 2871, Beijing 100085, P.R. China \\ 2 Agilent Technologies, Beijing, P.R. China
}

Received September 4, 2002; accepted February 11, 2003; published online May 15, 2003

(C) Springer-Verlag 2003

\begin{abstract}
Thirty-two breast milk samples provided voluntarily by healthy women living in the Dongting Lake area were investigated by Inductively Coupled Plasma Mass Spectrometry (ICP/MS). Eleven minor and trace elements ( $\mathrm{Na}, \mathrm{Mg}, \mathrm{K}, \mathrm{Ca}, \mathrm{Mn}, \mathrm{Fe}, \mathrm{Cu}, \mathrm{Zn}, \mathrm{As}$, $\mathrm{Se}$ and $\mathrm{Pb}$ ) were quantified and compared with literature reports. The results provide useful data for further studies in the nutritional field.
\end{abstract}

Key words: Breast milk; human milk; minor and trace elements; $\mathrm{ICP} / \mathrm{MS}$.

Essential minor and trace elements play an important role in human health, especially at the infant stage. Lack of these essential elements will cause deficiencies. Breast milk is the ideal nutrition for infants and usually the only dietary source for newborns. Although it was reported that the concentration of minor and trace elements in breast milk differs significantly depending on the areas mothers came from, it is believed that breast milk has good nutritional qualities even when mothers are poorly nourished [1]. There is great interest in investigating the level of essential elements in breast milk in a certain area. In order to study the concentration of essential elements in breast milk in a small, relatively closed off town around Dongting

\footnotetext{
* Author for correspondence. E-mail: zhengmh@mail. rcees.ac.cn
}

Lake located in southern China, samples were taken from local residents who were expected to give birth within two weeks. Minor and trace and toxic elements were analyzed, including $\mathrm{Na}, \mathrm{Mg}, \mathrm{K}, \mathrm{Ca}, \mathrm{Mn}, \mathrm{Fe}, \mathrm{Cu}$, $\mathrm{Zn}, \mathrm{As}, \mathrm{Se}$ and $\mathrm{Pb}$. $\mathrm{Pb}$ is a toxic element that can be absorbed by the human body. The half-life of $\mathrm{Pb}$ in blood, soft tissue and bone is 36 days, 40 days and 27 years, respectively [2].

Inductively Coupled Plasma Mass Spectrometry (ICP/MS) is a suitable tool for multi-element analysis of environmental samples [3-6]. It is a rapid, highly sensitive and accurate method for multi-element analysis, although it suffers certain matrix interference problem. In this study, the breast milk sample were digested with concentrated nitric acid and hydrogen peroxide at elevated temperature in order to eliminate the matrix interference problem followed by ICP/MS analysis.

\section{Experimental}

\section{Sample Collection}

Breast milks, which were transitional milks, were sampled voluntarily from healthy mothers who were expected to give birth within two weeks. Both mother and newborn were healthy. All mothers were native local residents either having lived in this area since their birth or for at least five years. They were between twenty-two and thirty-three years old. New clean and dried glassware was used for 
Table 1. Experimental parameters of the Agilent 7500-ICP-MS

\begin{tabular}{|c|c|c|c|c|c|}
\hline \multirow[b]{2}{*}{ Argon gas flow: } & \multirow{2}{*}{$\frac{\text { Plasma }}{14.0 \mathrm{~L} \cdot \mathrm{min}^{-1}}$} & \multicolumn{2}{|l|}{ Ion sampling } & \multicolumn{2}{|c|}{ Sensitivity CPS/ppb } \\
\hline & & Sample uptake rate: & $0.1 \mathrm{~mL} \cdot \min ^{-1}$ & $\operatorname{Li}(7):$ & 11757 \\
\hline Auxiliary gas flow: & $1.0 \mathrm{~L} \cdot \mathrm{min}^{-1}$ & Sampler and skimmer cones: & $\mathrm{Ni}$ & Y(89): & 22804 \\
\hline Sampling gas flow: & $1.0 \mathrm{~L} \cdot \min ^{-1}$ & Sampling depth: & $6.5 \mathrm{~mm}$ & $\mathrm{Tl}(205)$ & 222322 \\
\hline RF power: & $1350 \mathrm{~W}$ & Detection method: & Auto & & \\
\hline Nebulizer: & microconcentric & Repeat: & 3 & & \\
\hline Temperature of the spray chamber: & $2{ }^{\circ} \mathrm{C}$ & & & & \\
\hline
\end{tabular}

the sample collection. Collected breast milk samples were frozen and kept at $-10^{\circ} \mathrm{C}$ until analysis.

\section{Reagents and Standard Solutions}

Water purified with a Milli-Q deionized water system (Millipore, Bedford, MA, USA) was employed for preparing standard solutions and sample solutions in this experiment. Hewlett Packard MultiElement Calibration Standard-1 (Part\# 8500-6944, Lot\# 16-58AS) and Agilent Multi-Element Calibration Standard-2A (Part\# 85006940, Lot\# 20-74AS) were diluted to desired concentrations and served as standard solutions. All standard solutions contained $1 \%$ nitric acid (Fisher Tracer Element Grade, $68-70 \%$ v/v, USA) and were stored in PTFE bottles. Prior to use, bottles were cleaned by immerging in 15-20\% nitric solution over night, then boiled in an oven for three hours, washed with deionized water three to five times and dried.

Breast milk samples were digested with nitric acid hydrogen peroxide to destroy organic matrix by oxidation. To this end, $3 \mathrm{~mL}$ nitric acid and $1 \mathrm{~mL} \mathrm{H}_{2} \mathrm{O}_{2}$ (semiconductor grade) were transferred to a $30 \mathrm{~mL}$ digesting tube with aliquots of the breast milk samples $(1 \mathrm{~mL})$ and left at room temperature overnight. The following day they were sealed and heated to $100^{\circ} \mathrm{C}$ for one hour in an oven before temperature was raised to $150^{\circ} \mathrm{C}$. They were then kept there for another two hours before the heater was turned off and the samples were cooled for an additional three hours. At the end of digestion, sample solutions were transferred to another bottle and diluted with deionized water to produce a final weight of forty grams. A $5 \%$ nitric acid solution was treated as black. Certified Skim Milk Powder Reference Material (GBW 08509) was provided by the China National Standard Materials Research Center. Prior to sample analysis, the ICP-MS instrument was conditioned with stock tuning solution (Agilent, Part\# 8500-6943, Lot\# 17-56AS, USA) with the elements $\mathrm{Li}, \mathrm{Y}, \mathrm{Tl}, \mathrm{Ce}$.

\section{Experimental Parameters}

An Agilent 7500-ICP-MS (Tokyo Japan) equipped with a microconcentric nebulizer was employed for all experiments. All experiment parameters referred to the EPA method 200.8. [7, 8], optimum parameters are given in Table 1. This study employed the recommended elemental equations for data calculation from the ChemStation, which were also given in the EPA Method 200.8.

\section{Standardization and Sample Measurement}

The calibration curve was prepared according to the parameters listed in Table 1 . The calibration curve was prepared by analyzing a series of diluted Agilent Multi-Element Calibration Standard solutions, where 5\% nitric acid solution serves as blank. After obtaining the values of the elements in the reference materials, the values of those elements in breast milk samples were further calibrated against the values obtained from the reference materials.

\section{Results and Discussion}

The results from the standard reference materials are listed in Table 2. All values found agreed with the certified values, indicating that the instrument performed well under the given conditions at the time of sample analysis. In addition, the accuracy and precision of the method was sufficient for the experiment.

The statistic results from thirty-two transitory milk samples, collected five to twelve days after babies had been delivered, are listed in Table 3 and include the reference range suggested by the World Health Organization (WHO). The concentration level of trace elements may vary with the nationality of the breast milk provider, the maturity of breast milk, local geochemical conditions, food chain as well as air intake. Our survey indicated that mothers from the same area had similar diets. Thus, the concentration level was within a relatively narrow range, except that the maximum and minimum values of some elements were abnormal. The reason for these abnormal values may be due to (i) significant differences between persons with respect to the elements $\mathrm{Fe}, \mathrm{Zn}, \mathrm{Cu}, \mathrm{Ca}$ and $\mathrm{Mg}$ comparing the level of trace elements of the colostrum and transitory milk [9]

Table 2. Comparison of the found and certified values of reference materials

\begin{tabular}{lccc}
\hline Elements & Mass & $\begin{array}{l}\text { Certified value } \\
\pm \text { standard } \\
\text { deviation }\end{array}$ & $\begin{array}{l}\text { Found value } \\
\pm \text { standard } \\
\text { deviation }\end{array}$ \\
\hline $\mathrm{Na}(\mathrm{mg} / \mathrm{g})$ & 23 & $5.26 \pm 0.17$ & $5.30 \pm 0.06$ \\
$\mathrm{Mg}(\mathrm{mg} / \mathrm{g})$ & 24 & $1.30 \pm 0.05$ & $1.30 \pm 0.02$ \\
$\mathrm{~K}(\mathrm{mg} / \mathrm{g})$ & 39 & $18.6 \pm 0.5$ & $20.3 \pm 0.2$ \\
$\mathrm{Ca}(\mathrm{mg} / \mathrm{g})$ & 43 & $12.2 \pm 0.5$ & $15.6 \pm 0.2$ \\
$\mathrm{Zn}(\mu \mathrm{g} / \mathrm{g})$ & 66 & $46.8 \pm 2.8$ & $49.1 \pm 0.7$ \\
$\mathrm{Mn}(\mu \mathrm{g} / \mathrm{g})$ & 55 & $0.28 \pm 0.05$ & $0.25 \pm 0.01$ \\
$\mathrm{As}(\mu \mathrm{g} / \mathrm{g})$ & 75 & $(0.013)$ & $0.017 \pm 0.004$ \\
$\mathrm{Se}(\mu \mathrm{g} / \mathrm{g})$ & 82 & $0.22 \pm 0.02$ & $0.23 \pm 0.01$ \\
$\mathrm{~Pb}(\mu \mathrm{g} / \mathrm{g})$ & 207 & $0.034 \pm 0.010$ & $0.070 \pm 0.003$ \\
$\mathrm{Fe}(\mu \mathrm{g} / \mathrm{g})$ & 57 & $5.18 \pm 0.73$ & $5.23 \pm 0.08$ \\
$\mathrm{Cu}(\mu \mathrm{g} / \mathrm{g})$ & 63 & $0.26 \pm 0.05$ & $0.23 \pm 0.03$ \\
\hline
\end{tabular}


Table 3. Results obtained for minor and trace elements from thirty-two breast milk samples

\begin{tabular}{llccccc}
\hline Elements & $\begin{array}{l}\text { Average } \\
\text { value } \\
\begin{array}{l} \pm \text { standard } \\
\text { deviation }\end{array}\end{array}$ & Range & $\begin{array}{l}\text { Medium } \\
\text { value }\end{array}$ & $\begin{array}{l}25 \%-75 \% \\
\text { range }\end{array}$ & $\begin{array}{l}25 \%-75 \% \\
\text { range avg. } \\
\text { value }\end{array}$ & $\begin{array}{l}\text { Reference value } \\
\text { from literature }\end{array}$ \\
\hline $\mathrm{Na}(\mathrm{mg} / \mathrm{L})$ & $447 \pm 20$ & $151-2532$ & 380 & $298-430$ & 374.7 & n.a. \\
$\mathrm{Mg}(\mathrm{mg} / \mathrm{L})$ & $81.8 \pm 3.4$ & $53.1-559$ & 65.7 & $63.4-71.8$ & 66.9 & $9.50-62.5[10,11]$ \\
$\mathrm{K}(\mathrm{g} / \mathrm{L})$ & $1.04 \pm 0.04$ & $0.57-7.30$ & 0.83 & $0.78-0.88$ & 0.83 & n.a. \\
$\mathrm{Ca}(\mathrm{mg} / \mathrm{L})$ & $419 \pm 9.3$ & $180-5099$ & 272 & $225-308$ & 275 & $220-300[10,11]$ \\
$\mathrm{Mn}(\mu \mathrm{g} / \mathrm{L})$ & $113 \pm 5$ & $9.8-788$ & 52.5 & $31-131$ & 70.6 & $3-40[10,11]$ \\
$\mathrm{Fe}(\mathrm{mg} / \mathrm{L})$ & $3.71 \pm 0.24$ & $1.11-22.6$ & 2.26 & $1.82-2.64$ & 2.22 & $0.20-1.71[10,11]$ \\
$\mathrm{Cu}(\mathrm{mg} / \mathrm{L})$ & $0.699 \pm 0.032$ & $0.167-1.371$ & 0.701 & $0.605-0.772$ & 0.689 & $0.18-0.75[10,11]$ \\
$\mathrm{Zn}(\mathrm{mg} / \mathrm{L})$ & $13.1 \pm 0.5$ & $0.1-75.4$ & 7.9 & $5.3-9.7$ & 7.9 & $0.70-4.00[10,11]$ \\
$\mathrm{As}(\mu \mathrm{g} / \mathrm{L})$ & $20.8 \pm 8.3$ & $1.1-204$ & 11.2 & $4.7-27.3$ & 12.3 & n.a. \\
$\mathrm{Se}(\mu \mathrm{g} / \mathrm{L})$ & $17.6 \pm 0.4$ & $6.5-110$ & 14.5 & $11.2-18.3$ & 14.4 & $13-24[12]$ \\
$\mathrm{Pb}(\mu \mathrm{g} / \mathrm{L})$ & $5.33 \pm 0.47$ & $1.23-32.3$ & 3.40 & $2.89-4.92$ & 3.71 & $2-30[10,11]$ \\
\hline
\end{tabular}

n.a.: Not available.

and (ii) individual differences among volunteers. Further study should be performed to obtain more information.

The present study shows that the average concentration of lead within the $25 \%-75 \%$ range is $3.71 \mu \mathrm{g} / \mathrm{L}$, falling into the recommended range of $2-30 \mu \mathrm{g} / \mathrm{L}$. This indicated that the local residents were not suffering from lead pollution.

\section{The Distribution of Elements with Respect} to the Age of Mothers

All thirty-two samples were provided by volunteers who were between twenty-two and thirty-three years old. They were divided into four groups according to age. The average concentration of various elements with respect to age is plotted as a 3D figure in Fig. 1. It was found that the concentration level of most elements did not depend on the age of the mothers. However, some elements, such as Fe, Mn, As and Zn, showed that the average value of these elements in a certain age range was higher than in other age groups. The concentration level of $\mathrm{Fe}$ and $\mathrm{Mn}$ in the age group 25-27 was higher than in the other groups. The maximum average value of As appeared in the group 28-30, while the maximum average value of $\mathrm{Zn}$ appeared in the group 31-33.

\section{The Function Relation Between the Element} $\mathrm{Zn}$ and $\mathrm{Se}$

$\mathrm{Zn}$ and Se are not stored in the fetus while it grows in the uterus [4]. After five extreme data points have

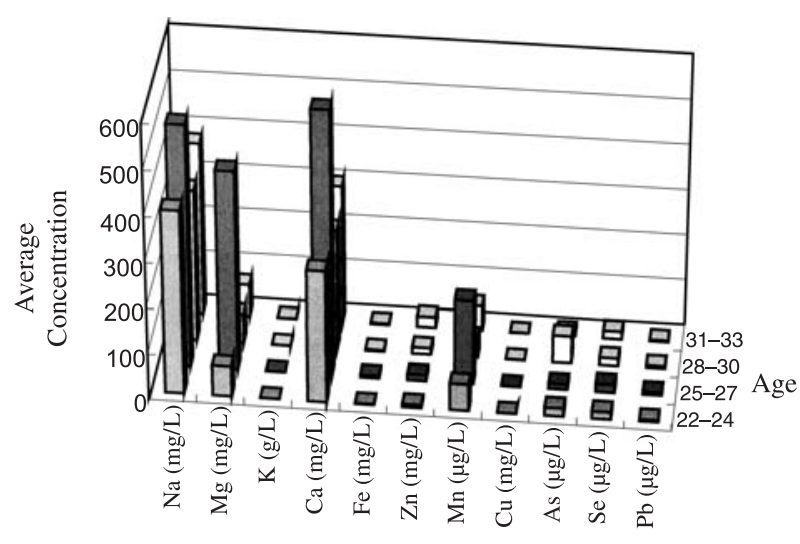

Element

Fig. 1. The concentration level of various element versus four age groups

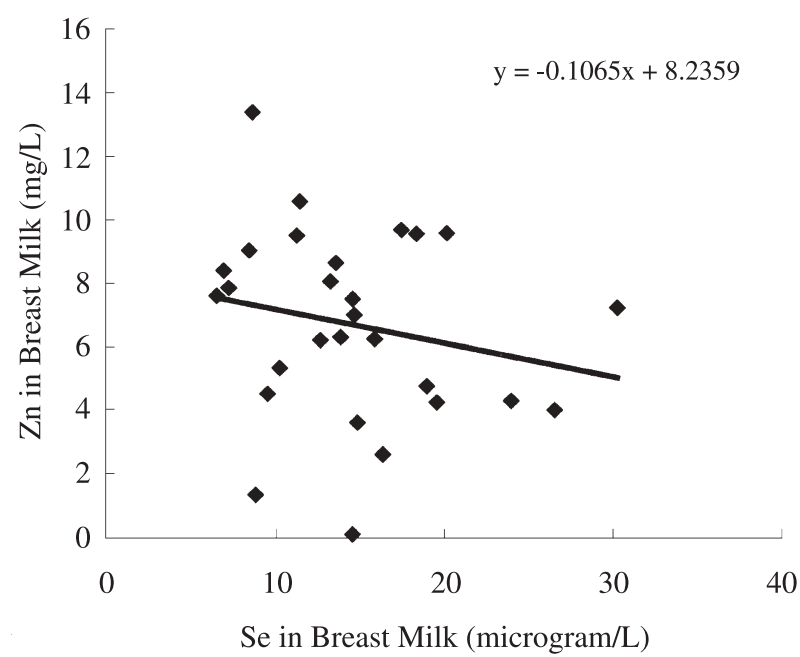

Fig. 2. The functional relationship between the element $\mathrm{Zn}$ and $\mathrm{Se}$ 
been eliminated, the level of $\mathrm{Zn}$ in breast milk versus that of Se in breast milk was plotted in Fig. 2. It was found that there was a linear relationship between the concentration of $\mathrm{Zn}$ and Se. This result agrees with the observation found by Brätter [5]. However, the $\mathrm{Zn}$ concentration in our case was higher than the $\mathrm{Zn}$ concentration reported, while the level of Se was lower.

\section{Conclusion}

The results indicate that the level of some essential elements, such as $\mathrm{Mg}, \mathrm{Fe}, \mathrm{Mn}$ and $\mathrm{Zn}$ in the area investigated, was higher than that recommended by WHO. The level of lead, the only toxic element studied, was within the normal range. The concentration level of most trace elements in transitory milks did not depend on the age of mothers except for some elements such as $\mathrm{Fe}, \mathrm{Mn}$, As and $\mathrm{Zn}$ which showed significantly higher average values in some age groups. The relation between $\mathrm{Zn}$ and Se agrees with the literature report, although the level of Se was on the low side of the recommended range suggested by WHO.
Acknowledgments. This study is supported by the Chinese Academy of Sciences (KZCX2-414).

\section{References}

[1] B. Lonnerdal, Nutrition Review 2000, 58(8), 223.

[2] M. Patriarca, A. Menditto, B. Rossi, T. D. B. Lyon, G. S. Fell, Microchem. Journal 2000, 67, 351.

[3] F. A. R. Martino, M. L. F. Sanchez, A. Sanz-Medel, Anal. Chim. Acta 2001, 442, 191.

[4] F. A. R. Martino, M. L. F. Sanchez, A. Sanz-Medel, J. Anal. At. Spectrom 2000, 15, 163.

[5] P. Brätter, I. N. Blasco, V. E. N. de Brätter, A. Raab, Analyst 1998, 123(5), 821.

[6] T. Prohaska, G. Kollensperger, M. Krachler, K. D. Winne, G. Stingeder, L. Moens, J. Anal. At. Spectrom 2000, 15, 335.

[7] S. E. Long, T. D. Martin, U.S. EPA Method 200.8, April 1991.

[8] E. Bakbwska, Environ. Chem. (China) 2001, 20, 616.

[9] Y. Hu, Y. Luo, L. Dai, C. Zhou, M. Cao, Y. Chen, Chinese Journal of Practical Gynecology and Obstetrics (China) 1998, 14, 303.

[10] E. Coni, B. Bocca, B. Galoppi, A. Alimonti, S. Caroli, Microchem. J. 2000, 67, 187.

[11] B. Bocca, A. Alimonti, E. Coni, M. D. Pasquale, L. Giglio, A. Piccioli Bocca, S. Caroli, Talanta 2000, 53, 295.

[12] Y. Jiang, Z. Lu, H. Fan, D. Qian, W. Shi, Y. Zhang, Studies of Trace Elements and Health (China) 1996, 13, 20-21. 